Agnieszka Doczekalska

\title{
(De)kulturyzacja i (de)hybrydyzacja języka prawnego w procesie tworzenia i transpozycji prawa Unii Europejskiej
}

\section{Wprowadzenie}

Prawo tworzone przez Unię Europejską jest jednolite i autonomiczne'. Powstaje z poszanowaniem różnorodności kultur, języków oraz tradycji i systemów prawnych poszczególnych państw członkowskich ${ }^{2}$. Wymóg zachowania jednolitości i autonomiczności prawa skutkuje dekulturyzacją, a poszanowanie różnorodności - hybrydyzacją unijnych tekstów prawnych. Z drugiej strony, kiedy prawo unijne jest stosowane w państwach członkowskich, a zwłaszcza transponowane do porządków prawnych tych państw, można zaobserwować procesy odwrotne, tj. kulturyzację i dehybrydyzację języka prawnego Unii Europejskiej³. W niniejszym tekście omawiam w szczególności dwa procesy, jakim podlega język prawny podczas tworzenia prawa unijnego (tj. dekulturyzację i hybrydyzację)

1 Na temat autonomiczności i odrębności systemu prawa wspólnotowego zob. R. Barents, The Autonomy of Community Law, Haga 2004 oraz W. Jedlecka, Z zagadnień autonomii prawa wspólnotowego, [w:] J. Kaczor (red.), Z zagadnień teorii i filozofii prawa. Teoria prawa europejskiego, Wrocław 2005, s. 113-128. Zob. wyrok Trybunału z dnia 15 lipca 1964 r. w sprawie C-6/64 Flaminio Costa przeciwko E.N.E.L., Zb. Orz. 1964, s. 585, pkt 3. Por. m.in. wyroki z 2012 r.: wyrok z dnia 3 lipca 2012 r. w sprawie C-128/11 UsedSoft GmbH przeciwko Oracle International Corp., niepublikowany w Zb. Orz., pkt 40; wyrok z dnia 26 kwietnia 2012 r. w sprawie C-510/10 DR i TV2 Danmark A/S przeciwko NCB - Nordisk Copyright Bureau, niepublikowany w Zb. Orz., pkt 34; wyrok z dnia 21 grudnia 2011 r. w sprawach połączonych Tomasz Ziolkowski (C-424/10) i Barbara Szeja i inni (C-425/10) przeciwko Land Berlin, Zb. Orz. 2011, s. I-14035, pkt 33.

2 O poszanowaniu systemów i tradycji państw członkowskich mówi art. 67 Traktatu o funkcjonowaniu Unii Europejskiej (wersja skonsolidowana Dz. Urz. UE C 326 z 26 października 2012 r.); o poszanowaniu różnorodności kulturowej i językowej mówi m.in. art. 3 Traktatu o Unii Europejskiej (wersja skonsolidowana Dz. Urz. UE C 326 z 26 października 2012 r.).

3 Na temat możliwości wyodrębnienia języka prawnego Unii Europejskiej zob. J. Boulouis, Quelques réflexions à propos du langage juridique communautaire, „Droits (Revue française de théorie juridique)" 1991, no. 14, s. 97-103 oraz M.-J. Campana, Vers un langage juridique commun en Europe?, „European Review of Private Law” 2000, no. 1, s. 33-50. 
oraz zwracam uwagę na dwa przeciwne procesy, występujące zwłaszcza podczas transpozycji dyrektyw unijnych do systemu prawnego państw członkowskich (tj. kulturyzację i dehybrydyzację).

\section{Hybrydyzacja podczas tworzenia unijnych tekstów prawnych}

Teksty hybrydowe powstają w środowisku wielojęzycznym i wielokulturowym, takim, jakim jest Unia Europejska ${ }^{4}$. Są tworzone w wyniku międzykulturowych negocjacji, powstają jako kompromis między różnymi kulturami i językami ${ }^{5}$. Mogą także powstać w wyniku przekładu, kiedy tłumacz przekazuje elementy kultury tekstu źródłowego adresatom tekstu docelowego. W takiej sytuacji tekst przetłumaczony, łącząc cechy językowe i kulturowe charakterystyczne zarówno dla kultury źródłowej, jak i docelowej, wydaje się adresatowi obcy, dziwny, czasem niezrozumiały. Nie jest to jednak błędem, a wynika ze świadomej decyzji tłumacza ${ }^{6}$. Zjawisko hybrydyzacji i pojęcie tekstu hybrydowego znalazło się w kręgu zainteresowań teorii przekładu pod koniec XX w. ${ }^{7}$ Według niektórych autorów każdy przekład jest tekstem hybrydowym ${ }^{8}$. Inni uważają, że tekst hybrydowy może powstać nawet bez dokonywania przekładu, tylko w wyniku kontaktu różnych języków i kultur ${ }^{9}$. Anthony Pym natomiast wskazuje, że to tekst źródłowy powstały w środowisku wielojęzycznym i wielokulturowym jest tekstem hybrydowym, który może ulec dehybrydyzacji dzięki przekładowi, w wyniku którego powstaje tekst w jednym języku i odzwierciedlający jedną kulturę ${ }^{10}$.

${ }^{4}$ Ch. Schäffner, B. Adab, The idea of the hybrid text in translation: Contact as conflict, „Across Languages and Cultures” 2001, no. 2 (2), s. 178.

5 Ch. Schäffner, B. Adab, Translation as intercultural communication - contact as conflict, [w:] M. Snell-Hornby, Z. Jettmarová, K. Kaindl (eds), Translation as Intercultural Communication, Amsterdam 1997, s. 329-330.

6 Tłumacz podejmuje decyzję, czy jego przekład będzie wierny językowi i kulturze docelowej, tzw. przekład zorientowany na odbiorcę. Wtedy może zostać spełniony warunek przezroczystości przekładu i niewidzialności tłumacza. Dzięki temu czytelnik może nawet nie zdawać sobie sprawy z tego, że ma do czynienia z przekładem tekstu napisanego w innym języku i pochodzącego z innej kultury. Tłumacz może również pozostać wierny kulturze i językowi źródłowemu. Wtedy powstanie przekład celowo nacechowany obcością. Taki tekst można określić jako hybrydowy. Zob. F. Schleiermacher, Über die verschiedenen Methoden des Übersetzens, Berlin 1813, a także L. Venuti, The Translator's Invisibility: A History of Translation, London-New York 2004.

7 Zob. T. Hermans, The Translator's Voice in Translated Narrative, „Target” 1996, no. 8 (1), s. 23-48; Ch. Schäffner, B. Adab, Translation as intercultural communication..., s. 325-337; A. Trosborg, Translating hybrid political texts, [w:] A. Trosborg (ed.), Text Typology and Translation, Amsterdam-Philadelphia PA 1997, s. 145-158.

8 Zob. T. Hermans, op. cit., s. 45, cyt. w: Ch. Schäffner, B. Adab, The idea of the Hybrid Text..., s. 170.

9 Zob. M. Snell-Hornby, The space 'in between': What is a hybrid text?, „Across Languages and Cultures" 2001, no. 2 (2), s. 209.

${ }^{10}$ Zob. A. Pym, Against praise of hybridity, „Across Languages and Cultures” 2001, no. 2 (2), s. 205, 207. 
Nie przyjęto do tej pory jednej wspólnej definicji tekstu hybrydowego. $\mathrm{Na}$ potrzeby tego artykułu będę posługiwać się definicją zaproponowaną przez A. Trosborg, według której tekst hybrydowy to „tekst, który powstaje w wyniku kontaktu dwóch lub więcej języków i kultur"'11. W teorii przekładu podkreśla się, że hybrydyzacja tekstu jest wynikiem świadomej decyzji tłumacza, nie wynika z błędu lub braku umiejętności ${ }^{12}$. Kiedy odnoszę termin „tekst hybrydowy" do aktów prawnych Unii Europejskiej, przyjmuję, że hybrydowość jest zamierzonym i celowym zabiegiem.

Przyczyną hybrydyzacji unijnych tekstów prawnych jest uwzględnianie różnorodności kultur i tradycji państw członkowskich podczas tworzenia prawa unijnego. Poszanowanie chociażby różnorodności językowej, przejawiające się w wymogu tworzenia prawa w 24 językach urzędowych ${ }^{13}$ powoduje, że powstaje tekst prawny, który można określić jako tekst hybrydowy. Hybrydowość tekstu prawa unijnego można analizować na dwóch poziomach: po pierwsze, na poziomie wielojęzycznego tekstu aktu prawnego oraz, po drugie, na poziomie poszczególnych wersji językowych ${ }^{14}$.

Prawo unijne jest tworzone, uchwalane i publikowane w 24 językach urzędo$w_{y c h}{ }^{15}$. Wszystkie wersje językowe są w równym stopniu autentyczne. Oznacza to, że tworzą one wspólnie znaczenie tekstu prawnego i żadna z wersji językowych nie może zostać odrzucona podczas dokonywania wykładni unijnego aktu prawnego ${ }^{16}$. Zasadę równej autentyczności wspiera teoria tekstów oryginalnych, która zakłada, że wszystkie autentyczne wersje językowe, bez względu na to, jak zostały stworzone, są oryginałami; żadna $\mathrm{z}$ wersji nie jest przekładem ${ }^{17}$. W przypadku

${ }^{11}$ A. Trosborg, Translating..., s. 147. Na tę cechę tekstów hybrydowych wskazują również Ch. Schäffner i B. Adab - zob. Translation as intercultural communication ..., s. 325.

${ }^{12}$ G. Palumbo, Key Terms in Translation Studies, London-New York 2009, s. 57.

${ }^{13}$ Zob. art. 1 i 4 rozporządzenia Rady nr 1/58 w sprawie określenia systemu językowego Europejskiej Wspólnoty Gospodarczej (Dz. Urz. L 17 z 6 października 1958 r., s. 385; wersja skonsolidowana z 1 lipca 2013 r. dostępna na: http://eur-lex.europa.eu).

${ }^{14} \mathrm{Na}$ temat różnic między terminem „tekst” i ,wersja” w języku prawnym i prawniczym Unii Europejskiej zob. A. Doczekalska, All Originals: Fiction and Reality of Multilingual Legal Drafting in the European Union and Canada, praca doktorska, The European University Institute, Florencja 2009, s. 20-21.

${ }^{15}$ Akty prawa pierwotnego są sporządzane i autentyczne we wszystkich językach urzędowych. W odniesieniu do aktów prawa pochodnego rozporządzenie Rady 1/58 wymaga, aby rozporządzenia i inne dokumenty powszechnie obowiązujące sporządzano w językach urzędowych (art. 4), a także by „Dziennik Urzędowy Unii Europejskiej” publikowano w językach urzędowych.

${ }^{16}$ Wyrok Trybunału z dnia 6 października 1982 r. w sprawie 283/81 Srl CILFIT i Lanificio di Gavardo SpA przeciwko Ministero della sanità, Zb. Orz. 1982, s. 3415, pkt 18. Zob. S. Šarčević, New Approach to Legal Translation, Haga-London-Boston 2000, s. 64.

${ }^{17}$ S. Šarčević New Approach..., s. 20; E. Wagner, Translation of multilingual instruments in the European Union, [w:] S. Šarčević (ed.) Legal Translation. Preparation for Accession to the European Union, Rijeka 2001, s. 67. 
Unii Europejskiej, chociażby z powodu przystępowania do Unii poszczególnych państw członkowskim w różnym czasie, teoria ta jest fikcją, która jednak pozwala na stosowanie zasady równej autentyczności. Na przykład zgodnie z teorią tekstów oryginalnych chorwackie wersje aktów prawa pierwotnego i pochodnego z dniem 1 lipca 2013 r., kiedy Chorwacja przystapiła do Unii Europejskiej, stały się oryginałami, mimo że nie powstawały wraz z innymi wersjami tych aktów ${ }^{18}$. Chorwacka wersja jest autentyczna na takich samych warunkach jak teksty sporządzone w pozostałych językach urzędowych. Jeżeli zatem nie mamy do czynienia z przekładem, który z reguły oznacza zastąpienie tekstu w jednym języku tekstem w innym języku, możemy mówić o wielojęzycznym tekście aktu prawnego, którego wersje nie zastępują siebie nawzajem, lecz współistnieją i współuczestniczą w tworzeniu znaczenia aktu prawnego. Kiedy Europejski Trybunał Sprawiedliwości, a obecnie Trybunał Sprawiedliwości Unii Europejskiej (TS UE), odnosi się do zasady równej autentyczności, z której wynika obowiązek poszukiwania wspólnego znaczenia dla wszystkich wersji językowych, posługuje się określeniem „wielojęzyczny tekst prawa unijnego"19. Zatem wielojęzyczny akt prawa Unii Europejskiej stanowi wyjątkowy przykład tekstu hybrydowego, którego pojawienie się wynika nie tyle z kontaktu języków, ile ze współistnienia 24 wersji językowych współtworzących znaczenie tego aktu.

Wymóg sporządzania aktów prawa unijnego w 24 językach jest realizowany przez instytucje Unii Europejskiej na większości etapów tworzenia prawa. W wyniku pozostawania języków urzędowych Unii w ciągłym kontakcie oraz ich oddziaływania na siebie powstają teksty hybrydowe, łączące w sobie cechy syntaktyczne, morfologiczne i leksykalne charakterystyczne dla wielu języków ${ }^{20}$. Osoby biorące udział w procesie tworzenia prawa (w szczególności tłumacze i prawnicy lingwiści odpowiedzialni za jakość tekstów aktów prawnych, a przede wszystkim za zapewnienie, aby wszystkie wersje językowe miały takie samo znaczenie) mają świadomość tego, że akt prawny jest wyrażany i autentyczny w 24 językach. Dlatego należy unikać terminów, które są nieprzetłumaczalne. Jeżeli okaże się, że został użyty termin lub sformułowanie, które nie ma odpowiednika chociażby w jednym z urzędowych języków UE, należy termin lub sformułowanie zastąpić innym przetłumaczalnym wyrażeniem. W ten sposób języki oddziałują na siebie.

${ }^{18}$ Akt dotyczący warunków przystąpienia Republiki Chorwacji oraz dostosowań w Traktacie o Unii Europejskiej, Traktacie o funkcjonowaniu Unii Europejskiej i Traktacie ustanawiającym Europejską Wspólnotę Energii Atomowej (Dz. Urz. UE L 112/21 z 24 kwietnia 2012 r.) przewiduje, że od dnia przystąpienia Chorwacji do UE teksty traktatów (art. 14 i 54) oraz teksty aktów instytucji przyjęte przed przystąpieniem (art. 52) i sporządzone w języku chorwackim są autentyczne na takich samych warunkach jak teksty sporządzone w obecnych językach urzędowych.

${ }^{19}$ Zob. np. wyrok Trybunału z dnia 20 listopada 2001 r. w sprawie C-268/99 Aldona Malgorzata Jany and Others przeciwko Staatssecretaris van Justitie, Zb. Orz. 2001, s. I-08615, pkt 47.

${ }^{20}$ I. Zauberga, Discourse interference in translation, „Across Languages and Cultures” 2001, no. 2 (2), s. 273. 
W poszczególnych wersjach językowych można również wskazać na wyrażenia, które pochodzą z języka obcego. Na przykład Vademecum tłumacza zawierające wskazówki dla polskich tłumaczy unijnych informuje, że ,[a]ngielskie skrótowce nazw programów, instytucji itp. w tłumaczeniu na język polski z reguły pozostają w wersji angielskiej, chyba że istnieje uzus stosowania skrótowców polskich"21.

Hybrydyzację tekstu, która jest zgodnie z definicją działaniem celowym ${ }^{22}$, należy odróżnić od sytuacji, w której oddziaływanie języków na siebie prowadzi do popełniania błędów w poszczególnych wersjach językowych. W polskich tekstach najbardziej widoczne są wpływy języka angielskiego, który jest językiem ponad $70 \%$ wszystkich tekstów tłumaczonych przez Dyrekcję Generalną ds. Tłumaczeń Pisemnych Komisji Europejskiej ${ }^{23}$. Najczęściej popełniane są błędy gramatyczne ${ }^{24}$, składniowe $^{25}$ i interpunkcyjne ${ }^{26}$, wynikające przede wszystkim ze stosowania kalek angielskich konstrukcji językowych. Mimo że błędy te są rezultatem kontaktu dwóch lub więcej języków, to jednak nie możemy tylko z tego powodu nazywać wersji językowej zawierającej błędy tekstem hybrydowym.

Język angielski, który po rozszerzeniu Unii w 2004 r. stał się de facto głównym językiem roboczym instytucji Unii Europejskiej, również ulega wpływom innych języków. Wynika to z tego, że językiem angielskim, który pełni rolę lingua franca, posługują się osoby, dla których nie jest on językiem ojczystym. Jest to źródłem trudności również w procesie tworzenia prawa. Projekt aktu prawnego, którego przygotowanie przez Komisję Europejską w języku angielskim, rzadziej w języku francuskim, rozpoczyna zwykłą procedurą ustawodawczą ${ }^{27}$, jest często sporządzany przez osoby, które nie są rodzimymi użytkownikami tych języków. Trudno w takiej sytuacji uniknąć wpływu języka ojczystego danej osoby na przygotowywany przez nią tekst. Czasami wpływy są tak silne, że niektóre sformułowania są niezrozumiałe dla użytkowników języka angielskiego. Nie możemy w takiej sytuacji mówić o hybrydyzacji tekstu, lecz raczej o „skażeniu” języka angielskiego przez

${ }^{21}$ Vademecum tlumacza. Wskazówki redakcyjne dla tlumaczy, wersja 12 (styczeń 2014 r.), Departament Języka Polskiego, Dyrekcja Generalna ds. Tłumaczeń Pisemnych, Komisja Europejska, Luksemburg 2007-2014, s. 52.

${ }^{22}$ G. Palumbo, op. cit., s. 57.

${ }^{23}$ Według Translating for a multilingual community (Luxembourg 2009, s. 6) 72,5\% wszystkich tłumaczonych tekstów stanowiły teksty w języku angielskim.

${ }^{24} \mathrm{~Np}$. kalka angielskiej konstrukcji gramatycznej polegająca na zastosowaniu bezokolicznika po wyrażeniu „wydaje się”. Przykład pochodzi z instrukcji dla polskich tłumaczy tekstów unijnych Common translation problems, dostępnej na stronie Dyrekcji Generalnej ds. Tłumaczeń Pisemnych http://ec.europa.eu/translation/index_en.htm (dostęp: maj 2013).

${ }^{25} \mathrm{~Np}$. kalkowanie składni szyku datum novum. Przykład pochodzi z instrukcji dla polskich tłumaczy tekstów unijnych Common translation problems.

${ }^{26} \mathrm{~Np}$. kalkowanie angielskiej interpunkcji poprzez stawianie przecinka po wyrażeniu „na przykład”. Przykład pochodzi z instrukcji dla polskich tłumaczy tekstów unijnych Common translation problems.

${ }^{27}$ Art. 294 Traktatu o funkcjonowaniu Unii Europejskiej. 
kalki i zapożyczenia $z$ innego języka ${ }^{28}$. Na podstawie angielskiej wersji projektu aktu prawnego sporządzane są następnie pozostałe wersje językowe, ponieważ Komisja przedstawia projekt Parlamentowi Europejskiemu i Radzie we wszystkich 24 wersjach językowych. Mogło się zatem zdarzyć, że angielski tekst będący de facto oryginalną wersją - tekstem źródłowym ${ }^{29}$ - jest gorszej jakości niż thumaczenia. Aby poprawić jakość angielskich wersji językowych, od kilku lat w Dyrekcji Generalnej ds. Tłumaczeń Pisemnych pracują rodzimi użytkownicy języka angielskiego, a także języka francuskiego, których zadaniem jest weryfikowanie i edytowanie tekstów sporządzanych w wymienionych językach przez osoby, dla których języki te nie są językami ojczystymi ${ }^{30}$. Praca edytorów, wskazówki redakcyjne dla tłumaczy oraz innych osób uczestniczących w tworzeniu prawa unijnego, listy najczęściej popełnianych błędów w poszczególnych językach, kampanie poświęcone jasnemu i czytelnemu pisaniu tekstów - mają na celu wyeliminowanie niepożąanych wzajemnych wpływów języków pozostających w kontakcie.

\section{Dekulturyzacja podczas tworzenia unijnych tekstów prawnych}

Europejski Trybunał Sprawiedliwości wielokrotnie podkreślał, że prawo unijne tworzy odrębny system prawny ${ }^{31}$, który posługuje się swoimi własnymi pojęciami i terminami, charakterystycznymi tylko dla prawa unijnego ${ }^{32}$. Trybunał w szczególności podkreśla, że pojęcia prawne mają inne znaczenie

${ }^{28}$ Wyrażenie ,skażony język angielski” zostało użyte przez Manuelę Guggeis, która kieruje jednostką prawników lingwistów w Służbie Prawnej Komisji Europejskiej - zob. M. Guggeis, Multilingual legislation and the legal linguistic revision at the Council of the European Union, [w:] B. Pozzo, V. Jacometti (eds), Multilingualism and the Harmonisation of European Law, London 2006, s. 115; Study on Lawmaking in the EU Multilingual Environment, Luxembourg 2010, s. 19.

${ }^{29}$ Tekst ten de facto jest tekstem oryginalnym, a pozostałe wersje - tłumaczeniami, jednak de iure wszystkie wersje językowe aktu prawnego po jego przyjęciu są oryginałami zgodnie ze wspomnianą wcześniej teorią tekstów oryginalnych oraz z zasadą równej autentyczności.

${ }^{30} \mathrm{O}$ edytowaniu tekstów w Komisji pisze A. C. Murphy, Mediated language in non-native speaker texts from the European Commission, [w:] C. Taylor (ed.), Ecolingua. The Role of E-corpora in Translation and Language Learning, Trieste 2009, s. 173.

${ }^{31}$ Por. m.in. wyrok z dnia 15 lipca 1964 r. w sprawie C-6/64 Flaminio Costa przeciwko E.N.E.L., Zb. Orz. 1964, s. 585, pkt 3 lub wyrok z dnia 18 grudnia 2008 r. w sprawie Government of Gibraltar (T-211/04) i Zjednoczone Królestwo Wielkiej Brytanii i Irlandii Północnej (T-215/04) przeciwko Komisji Wspólnot Europejskich, Zb. Orz. 2008, s. II-03745, pkt 59, w których Trybunał wskazał, że prawo wspólnotowe ustanawia swój własny porządek prawny. Por. także m.in. wyrok z dnia 3 kwietnia 1968 r. w sprawie 28/67 firma Molkerei-Zentrale Westfalen/Lippe GmbH przeciwko Hauptzollamt Paderborn, Zb. Orz. 1968, s. 00143, pkt 1 lub wyrok z dnia 13 lutego 1969 r. w sprawie 14/68 Walt Wilhelm przeciwko Bundeskartellamt, Zb. Orz. 1969, s. 00001, pkt 1, w których Trybunał wskazał, że Wspólnota tworzy nowy system prawny.

${ }^{32}$ Wyrok Trybunału z dnia 6 października 1982 r. w sprawie 283/81 Srl CILFIT i Lanificio di Gavardo SpA przeciwko Ministero della sanità, Zb. Orz. 1982, s. 3415, pkt 19. 
w prawie wspólnotowym i w prawie poszczególnych państw członkowskich ${ }^{33}$. Ta uwaga interpretacyjna, wyrażona po raz pierwszy w 1982 r. w sprawie Cilfit, stanowi również wskazówkę dla twórców prawa unijnego. Jako że pojęcia prawa unijnego są pojęciami autonomicznymi, właściwymi dla prawa $\mathrm{UE}^{34}$, tworząc akty tego prawa „należy unikać sformułowań, które zbyt ściśle związane są z krajowym systemem prawnym" 35 . Zatem aby zastosować odpowiednie terminy na oznaczenie pojęć prawa unijnego, najpierw ustala się w poszczególnych językach urzędowych terminy stosowane na oznaczenie danego pojęcia w porządkach prawnych państw członkowskich, po to, aby odrzucić te terminy i zastosować inne terminy niezwiązane $\mathrm{z}$ prawem krajowym ${ }^{36}$. Pozwala to na osiągnięcie zgodności między wersjami językowymi oraz jednolite stosowanie prawa unijnego we wszystkich państwach członkowskich.

Istnieją różne metody odnajdywania lub tworzenia terminów, które nie są charakterystyczne dla krajowych porządków prawnych. Możliwe jest tworzenie i wprowadzanie nowych terminów, określanych jako euronimy ${ }^{37}$, np. komitologia. Domenico Cosmai zauważa, że często stosowane są hiperonimy ${ }^{38}$. Innym sposobem realizacji postulatu stosowania terminów niezwiązanych z prawem krajowym jest np. zastosowanie terminów znanych w językach prawnych państw członkowskich (lub jednego z nich) i nadanie im nowego znaczenia (tzw. resemantyzacja) ${ }^{39}$. Przykładem resemantyzacji jest francuski termin avocat général (ang. Advocate General) wybrany na określenie instytucji rzecznika generalnego, którego zadaniem jest, zgodnie z Traktatem o funkcjonowaniu Unii Europejskiej ${ }^{40}$, publiczne przedstawianie, przy zachowaniu całkowitej bezstronności i niezależności, uzasadnionych wniosków w niektórych sprawach wnoszonych do Trybunału Sprawiedliwości Unii Europejskiej, w celu wspomagania

33 Ibidem.

${ }^{34}$ Istnieje bogate orzecznictwo, w którym Trybunał wskazuje, że poszczególne terminy oznaczają autonomiczne pojęcia prawa Unii, które wobec tego należy interpretować na terytorium UE w sposób jednolity. Por. m.in. wyroki z 2012 r.: wyrok z dnia 3 lipca 2012 r. w sprawie C-128/11 UsedSoft GmbH przeciwko Oracle International Corp., pkt 40; wyrok z dnia 26 kwietnia 2012 r. w sprawie C-510/10 DR i TV2 Danmark A/S przeciwko NCB - Nordisk Copyright Bureau, pkt 34; wyrok z dnia 21 grudnia 2011 r. w sprawach połączonych Tomasz Ziolkowski (C-424/10) i Barbara Szeja i inni (C-425/10) przeciwko Land Berlin, pkt 33.

${ }^{35}$ Wymóg ten jest wyraźnie wskazany w zasadzie 5.3.2. Wspólnego przewodnika praktycznego dotyczacego redagowania aktów prawa wspólnotowego.

${ }^{36} \mathrm{Na}$ podstawie wypowiedzi uzyskanej podczas wywiadu z prawnikami lingwistami w instytucjach UE we wrześniu $2011 \mathrm{r}$.

37 Zob. R. Goffin, L'Eurolecte: oui, jargon communautaire: non, „Meta” 1994, no. XXXIX (4), s. 641, który wprowadza francuski termin: euronym.

38 D. Cosmai, Tradurre per l'Unione Europea, ed. 2, Milano 2007.

39 Zob. T. Gallas, Understanding EC law as 'diplomatic law' and its language, [w:] B. Pozzo, V. Jacometti (eds), op. cit., s. 127.

${ }^{40}$ Art. 252 Traktatu o funkcjonowaniu Unii Europejskiej. 
go w wykonywaniu powierzonego mu zadania. Regulacja dotycząca unijnego rzecznika generalnego oparta jest na znanej prawu francuskiemu instytucji commissaire du gouvernement, który pełni w Conseil d'État podobną rolę jak rzecznik generalny w TS UE ${ }^{41}$. Na oznaczenie pojęcia „rzecznik generalny” wybrano jednak inny francuski termin prawny avocat général, który jest również znany francuskiemu systemowi prawnemu i oznacza urzędnika sądowego prezentującego sprawę przed francuskim Sądem Kasacyjnym oraz wspierającego prokuratora generalnego $\mathrm{w}$ postępowaniu ${ }^{42}$. Zatem znaczenie terminu avocat général $\mathrm{w}$ prawie francuskim i w prawie unijnym jest zupełnie inne i stosowane jest na oznaczenie innych pojęć.

Czasem resemantyzacji podlega termin, który nie jest terminem prawnym lub prawniczym. Na przykład wyraz ,transpozycja”, który w języku polskim oznacza „przenosić z jednej dziedziny do innej, przystosowywać coś do czegoś" ${ }^{43}$ jest w Unii Europejskiej stosowany w ściśle określonym znaczeniu i oznacza ,wprowadzeni[e] przepisów aktu normatywnego przyjętego na szczeblu UE/WE (najczęściej dyrektywy, ale nie tylko) do aktów prawa krajowego [...], co wiąże się następnie z przyjęciem, publikacją i wejściem w życie danych aktów krajowych"44. Termin „transpozycja” należy odróżnić od wyrażenia „wdrożenie aktów prawnych Unii Europejskiej”. Wdrożenie, które często jest nieprawidłowo zastępowane słowem ,implementacja"45, jest szerszym pojęciem niż transpozycja i oznacza „transpozycję danego aktu UE oraz podjęcie wszelkich czynności w celu zapewnienia stosowania odnośnych przepisów krajowych w praktyce"46. Rada Języka Polskiego wielokrotnie wskazywała, że rzeczownik ,implementacja” i czasownik ,implementować” są zbędnymi anglicyzmami ${ }^{47}$. „Implementacja” jest zatem błędnym przekładem angielskiego słowa. Zaleca się, aby implementation w odniesieniu do aktów prawnych Unii Europejskiej tłumaczyć jako „wdrożenie” lub „wykonanie" Unii Europejskiej. Wyszukiwanie w bazie danych EUR-Lex wyrażenia „implementacja dyrektywy" dało mniej niż 20 rezultatów ${ }^{49}$. Natomiast zapytanie

${ }^{41}$ K. Borgsmidt, The Advocate General at the European Court of Justice: a comparative study, „European Law Review” 1988, no. 13 (2), s. 106-119 oraz A. A. Dashwood, The Advocate General in the Court of Justice of the European Communities, „Legal Studies” 1982, s. 202-215.

${ }^{42}$ A. A. Dashwood, op. cit.

${ }^{43}$ L. Wiśniakowska, Stownik wyrazów obcych PWN, Warszawa 2007.

${ }^{44}$ Vademecum tlumacza..., s. 82.

${ }^{45}$ Brukselizm będący zapożyczeniem angielskiego terminu implementation.

${ }^{46}$ Vademecum tlumacza..., s. 82.

${ }^{47}$ Zob. sprawozdania Rady Języka Polskiego: Sprawozdanie o stanie ochrony języka polskiego za lata 2003-2004 oraz Sprawozdanie ze stanu ochrony języka polskiego w latach 2008-2009, dostępne na: www.rjp.pan.pl/index.php.

${ }^{48}$ Vademecum tlumacza..., s. 82.

${ }^{49} \mathrm{http} / / /$ eur-lex.europa.eu/pl/index.htm (dostęp: maj 2013). 
dotyczące wyrażenia „wdrożenie dyrektywy” przyniosło 320 rezultatów, a sformułowania „transpozycja dyrektywy” - 390 rezultatów. Wyniki z wyszukiwarki Google pokazały, że o wiele częściej stosuje się wyrażenie „implementacja dyrektywy” (20 700 rezultatów) i „wdrożenie dyrektywy” (22 700) niż „transpozycja dyrektywy” (9900 rezultatów).

W wyniku stosowania opisanych metod wyszukiwania terminów prawa UE tekst unijnego aktu prawnego jest odbierany - zwłaszcza wtedy, kiedy adresat tekstu zapoznaje się z nim w swoim języku ojczystym - jako obcy i czasem niezrozumiały $^{50}$. Nie jest to jednak wynikiem błędów lub braku umiejętności twórców prawa unijnego, lecz zamierzonym zabiegiem, przez niektórych autorów określanym jako dekulturyzacja języków prawnych państw członkowskich ${ }^{51}$. Polega ona na usuwaniu z języka prawnego państw członkowskich elementów (terminów, wyrażeń, sposobu zapisu poszczególnych części aktu prawnego) charakterystycznych dla tego języka i zastępowaniu ich elementami neutralnymi. W wyniku dekulturyzacji powstaje język autonomicznego prawa UE.

\section{Dekulturyzacja i kulturyzacja podczas transpozycji unijnych dyrektyw do krajowego systemu prawnego}

Podczas transpozycji dyrektyw do systemu prawa krajowego, która najczęściej wiąże się z ustanowieniem nowego aktu prawnego lub wprowadzeniem odpowiednich zmian do obowiązującego aktu prawa krajowego, neutralne, niewiążące się z żadnym systemem prawnym terminy są zastępowane terminami właściwymi dla danego systemu prawa krajowego. Jak ujmuje to J. M. Smits, neutralne terminy tworzone i stosowane na poziomie Unii Europejskiej są często przekładane na język i terminologię prawa krajowego $^{52}$. Można wskazać kilka sytuacji, kiedy neutralne terminy zastępowane są terminami charakterystycznymi dla krajowego porządku prawnego ${ }^{53}$.

${ }^{50}$ Dlatego na określenie języka Unii Europejskiej używa się pejoratywnych wyrażeń, takich jak: ang. Eurofog - 'euro-mgła', ang. Eurobabble lub fr. l'eurobabillage - 'euro-bełkot'. Zob. R. Goffin, op. cit., s. 636.

${ }^{51}$ Ł. Biel, Translation of multilingual EU legislation as a sub-genre of legal translation, [w:] D. Kierzkowska (ed.), Court Interpreting and Legal Translation in the Enlarged Europe, Warsaw 2006; Th. van Els, The European Union, its institutions and its languages: Some language political observations, „Current Issues in Language Planning” 2001, vol. 2, no. 4, s. 311-360. Na temat wpływu procesu dekulturyzacji na konwergencję kultur prawnych zob. A. Doczekalska, Wielojęzyczność prawa a konwergencja kultur prawnych w Europie i Kanadzie, [w:] O. Nawrot, S. Sykuna, J. Zajadło (red.), Konwergencja czy dywergencja kultur i systemów prawnych?, Warszawa 2012, s. 176-180.

52 J. M. Smits, The Europeanisation of national legal systems: some consequences for legal thinking in civil law countries, [w:] M. van Hoecke (red.), Epistemology and Methodology of Comparative Law, Oxford 2004, s. 235.

${ }^{53}$ Zob. A. Doczekalska, All Originals..., s. 247-251. 
Po pierwsze, ustawodawca krajowy decyduje się czasem na zastąpienie terminu unijnego terminem występującym w języku prawnym państwa członkowskiego wtedy, gdy pojęcie, do którego odwołuje się dyrektywa unijna, jest znane również w krajowym systemie prawnym, jednak termin zastosowany do oznaczenia tego pojęcia w prawie krajowym różni się od terminu użytego w dyrektywie. Taka praktyka jest dopuszczalna tylko wówczas, gdy pozwala na interpretowanie danego pojęcia w sposób jednolity na terytorium całej Unii Europejskiej oraz nie prowadzi do przyjęcia, że dane pojęcie jest wyłącznie pojęciem krajowego porządku prawnego. Na przykład polski ustawodawca, uchwalając ustawę transponującą dyrektywę 2005/29/WE Parlamentu Europejskiego i Rady z dnia 11 maja 2005 r. dotyczącą nieuczciwych praktyk handlowych ${ }^{54}$, która przewiduje, że jedną z przesłanek pozwalających na zakwalifikowanie praktyki przedsiębiorcy jako nieuczciwej jest sprzeczność z wymogami staranności zawodowej (ang. professional diligence), postanowił zastąpić wyrażenie ,staranność zawodowa” znanym polskiemu prawu terminem „dobre obyczaje" 55 (tab. 1).

Po drugie, podobna sytuacja ma miejsce wówczas, gdy termin użyty w dyrektywie nie jest znany ustawodawstwu krajowemu, ale jest bardzo zbliżony do innego terminu krajowego, który ma jednak inne znaczenie niż termin użyty w dyrektywie. Przykład takiej sytuacji można również znaleźć w dyrektywie dotyczącej nieuczciwych praktyk handlowych, zaliczającej do agresywnych praktyk handlowych praktyki posługujące się bezprawnym naciskiem (ang. undue influence). W ustawie transponującej dyrektywę zdecydowano się posłużyć terminem „niedopuszczalny nacisk” zamiast wyrażaniem „bezprawny nacisk”, które jest zbliżone do terminu polskiego prawa karnego „groźba bezprawna" ${ }^{56}$. Ustawa zmienia nazwę, ale definiując pojęcie „niedopuszczalny nacisk”, stosuje zabieg niemalże „lustrzanego odbicia” definicji z dyrektywy ${ }^{57}$ (tab. 1).

Po trzecie, posłużenie się innym terminem niż użyty w dyrektywie może być zabiegiem pożądanym, pozwalającym uniknąć błędnej interpretacji. Ma to miejsce wtedy, gdy termin zastosowany w dyrektywie funkcjonuje również w języku prawa krajowego, ale ma inne znaczenie niż znaczenie nadane temu terminowi w dyrektywie. Przykładem takiej zmiany jest zastąpienie terminu „pomoc prawna” (ang. legal aid), którym posługuje się dyrektywa Rady 2003/8/WE z dnia 27 stycznia

${ }^{54}$ Dz. Urz. UE L 26 z 31 stycznia 2003 r.

55 Art. 4 . ust. 1 ustawy z dnia 23 sierpnia 2007 r. o przeciwdziałaniu nieuczciwym praktykom rynkowym, Dz. U. 2007, nr 171, poz. 1206. Zob. Uzasadnienie rzqdowego projektu ustawy o przeciwdziałaniu nieuczciwym praktykom rynkowym, druk sejmowy nr 1682.

${ }^{56}$ Zob. Uzasadnienie rzqdowego projektu ustawy o przeciwdziałaniu nieuczciwym praktykom rynkowym; na temat analizy ekwiwalentów undue influence użytych w innych wersjach językowych dyrektywy zob.: A. Doczekalska, All Originals..., s. 248-249.

${ }^{57}$ Art. 8. ust. 2 ustawy z dnia 23 sierpnia 2007 r. o przeciwdziałaniu nieuczciwym praktykom rynkowym. 
2003 r. w celu usprawnienia dostępu do wymiaru sprawiedliwości w sporach transgranicznych ${ }^{58}$, terminem ,prawo pomocy”, użytym w transponującej ustawie z dnia 17 grudnia 2004 r. o prawie pomocy w postępowaniu w sprawach cywilnych prowadzonym w państwach członkowskich Unii Europejskiej ${ }^{59}$. Użyty w dyrektywie termin ,pomoc prawna” w polskim prawie ma dwa znaczenia. Po pierwsze, oznacza pomoc, jaką polskim sądom udzielają sądy i inne organy państw obcych oraz polskie przedstawicielstwa dyplomatyczne i urzędy konsularne ${ }^{60}$. Po drugie, może oznaczać pomoc udzielaną przez adwokatów i radców prawnych osobom fizycznym i osobom prawnym. Pojęcie, którym posługuje się dyrektywa, jest zbliżone do drugiego znaczenia terminu ,,pomoc prawna”. Jednak znaczenie pojęcia unijnego jest szersze niż pojęcia polskiego, ponieważ oprócz ustanowienia adwokata lub radcy prawnego obejmuje też zwolnienie od kosztów sądowych. Aby uniknąć nieporozumień, zdecydowano się w ustawie transponującej dyrektywę na zastąpienie terminu ,pomoc prawna” wyrażeniem ,,prawo pomocy”61 (tab. 1).

Tabela 1. Przykład zmiany terminów prawa unijnego podczas transpozycji dyrektyw unijnych do krajowego systemu prawnego

\begin{tabular}{|c|c|c|}
\hline \multicolumn{2}{|c|}{ Prawo UE } & Polski akt prawny transponujący dyrektywę \\
\hline \multicolumn{2}{|c|}{$\begin{array}{l}\text { Dyrektywa 2005/29/WE Parlamentu } \\
\text { Europejskiego i Rady z dnia } 11 \text { maja } 2005 \text { r. } \\
\text { dotycząca nieuczciwych praktyk handlowych, } \\
\text { Dz. Urz. UE L } 149 \text { z } 11 \text { czerwca } 2005 \text { r. }\end{array}$} & $\begin{array}{l}\text { Ustawa z dnia } 23 \text { sierpnia } 2007 \text { r. } \\
\text { o przeciwdziałaniu nieuczciwym praktykom } \\
\text { rynkowym, Dz. U. 2007, nr 171, poz. } 1206\end{array}$ \\
\hline $\begin{array}{l}\text { ang. professional } \\
\text { diligence }\end{array}$ & $\begin{array}{l}\text { pl. staranność } \\
\text { zawodowa }\end{array}$ & dobre obyczaje \\
\hline ang. undue influence & pl. bezprawny nacisk & niedopuszczalny nacisk \\
\hline \multicolumn{2}{|c|}{$\begin{array}{l}\text { Dyrektywa Rady } 2003 / 8 / \text { WE z dnia } 27 \\
\text { stycznia } 2003 \text { r. w celu usprawnienia dostępu } \\
\text { do wymiaru sprawiedliwości w sporach } \\
\text { transgranicznych, Dz. Urz. UE L } 26 \text { z } 31 \\
\text { stycznia } 2003 \text { r. }\end{array}$} & $\begin{array}{l}\text { Ustawa z dnia } 17 \text { grudnia } 2004 \text { r. o prawie } \\
\text { pomocy w postępowaniu w sprawach } \\
\text { cywilnych prowadzonym w państwach } \\
\text { członkowskich Unii Europejskiej, } \\
\text { Dz. U. } 2005, \text { nr 10, poz. } 67\end{array}$ \\
\hline ang. legal aid & 1. pomoc prawna & prawo pomocy \\
\hline
\end{tabular}

Źródło: opracowanie własne.

Podczas transpozycji dyrektywy do porządku prawnego państwa członkowskiego następuje również dehybrydyzacja języka prawnego, ponieważ akt prawny transponujący dyrektywę jest tworzony zgodnie z zasadami techniki prawodawczej przyjętymi w prawie krajowym oraz w języku prawnym (najczęściej tylko w jednym) prawa państw członkowskich.

${ }^{58}$ Dz. Urz. UE L 26 z 31 stycznia 2003 r.

${ }^{59}$ Dz. U. 2005, nr 10, poz. 67.

${ }^{60}$ Art. 1130 k.p.c.

${ }^{61}$ Zob. Uzasadnienie rzqdowego projektu ustawy o prawie pomocy w postępowaniu $w$ sprawach cywilnych, prowadzonym w państwach członkowskich Unii Europejskiej, druk sejmowy nr 3261. 


\section{Podsumowanie}

Hybrydowość tekstu powstaje nie w wyniku błędów lub braku kompetencji twórcy tekstu, ale jest jego świadomą decyzją. Podobnie w przypadku unijnych aktów prawnych - ich hybrydyzacja i dekulturyzacja jest zamierzonym zabiegiem, którego celem jest sprawienie, aby tekst i język prawny był rozpoznawalny jako należący do systemu prawa Unii Europejskiej.

Gdy tekst hybrydowy zostanie zaakceptowany przez adresatów, a odbiorca nie będzie dostrzegał hybrydowości tekstu, tzn. obcych elementów w tym tekście, wtedy tekst przestaje być tekstem hybrydowym ${ }^{62}$. Zatem tekst hybrydowy jest zjawiskiem przejściowym, pozwalającym wprowadzić do danej kultury nowe elementy i pojęcia. Hybrydowość jest przez niektórych traktowana nie jako cecha tekstu, lecz jako proces, który pojawia się wtedy, kiedy powstaje nowa kultura ${ }^{63}$ - w omawianym przypadku kultura prawna Unii Europejskiej. W wyniku hybrydyzacji i dekulturyzacji języków prawnych państw członkowskich unijny tekst prawny, nawet jeśli zostanie zaakceptowany przez odbiorców i nie będzie dawał poczucia obcości, będzie jednak rozpoznawany jako element porządku prawnego Unii Europejskiej, a nie systemu krajowego.

${ }^{62}$ Ch. Schäffner, B. Adab, The idea of the Hybrid Text..., s. 178.

${ }^{63}$ Ibidem, s. 291. 